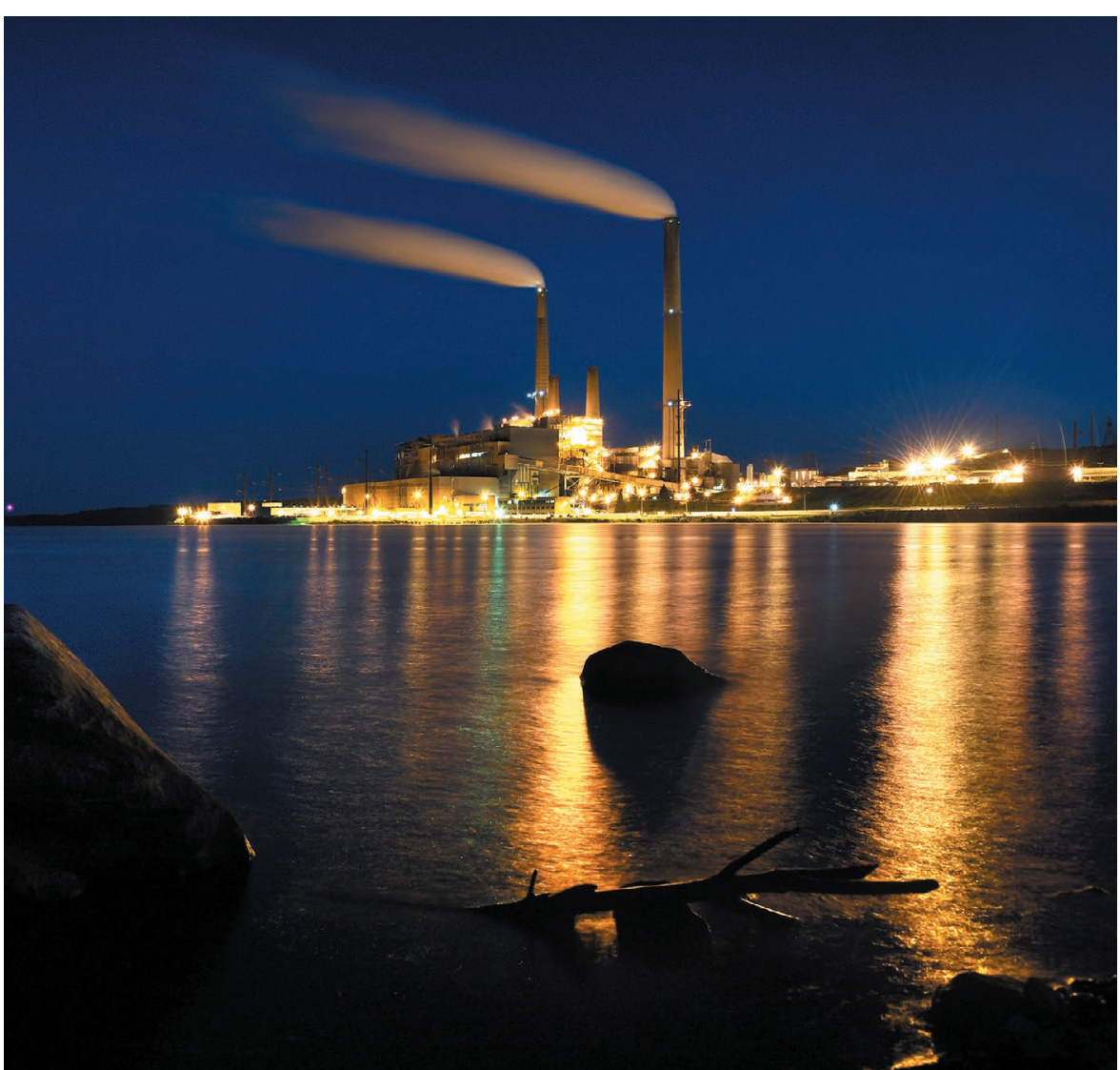

The Mount Storm power station in West Virginia can burn more than 15,000 tonnes of coal per day.

\section{Boycott products from states with}

\section{Consumer pressure could encourage regions to switch from fossil fuels to cleaner sources of electricity, argues Christopher Kennedy.}

I n 2014, electricity generation in the state of Kentucky was the most carbonintensive in the United States, and ranked among the highest anywhere in the world. Fuelled $90 \%$ by coal, the state's power plants emitted 945 tonnes of carbon dioxide (or the equivalent) for each unit of electricity they produced (in gigawatt hours) (see go.nature. com/2zaf6c2), and accounted for more than $60 \%$ of all Kentucky's $\mathrm{CO}_{2}$ emissions (see go.nature.com/2hamatv). This carbon intensity was almost a hundred times greater than in hydropowered Vermont (10 tonnes). Kentucky also exceeded China's average
(680 tonnes in 2014) and was comparable to China's worst province, Inner Mongolia (947 tonnes in 2013; see 'Regional ranges'). By 2016, although coal-powered generation in Kentucky had declined by $20 \%$ since 2014 , the state still had the third-highest share of coal in its electricity mix in the United States - after West Virginia and Wyoming (see go.nature.com/2zlijjm).

Driving an electric car in Kentucky or most Chinese provinces today produces more life-cycle emissions than are saved from the exhaust pipe of an equivalent petrol or diesel car. 'Dirty power' - processes that generate more than 600 tonnes of $\mathrm{CO}_{2}$ equivalent per gigawatt hour $\left(\mathrm{CO}_{2} \mathrm{e}\right.$ $\mathrm{GWh}^{-1}$ ) - turns on its head the goal of electrifying transport to reduce carbon emissions ${ }^{1}$. Electricity is also used to manufacture goods - such as cars, lorries and domestic appliances - that are purchased by consumers around the country and abroad.

I believe that if consumers recognized the problem of dirty power, many would choose not to buy products made in states such as Kentucky. Manufacturers might decide not to make goods there, would source their own clean power and would call on a state to clean up its act. Corporations and public pressure can drive environmental action even if national or state governments are not on board ${ }^{2}$. But consumers and firms need clear information to direct their purchasing power.

Companies are getting better at evaluating the environmental impacts of their products and supply chains, and at conveying that information to consumers. The London-based Carbon Trust, for example, has certified more than 25,000 products for its Product Footprint label, which calculates a product's total lifetime emissions from production, distribution and use. The Japan Environmental Management Association for Industry, based in Tokyo, reports carbon emissions associated with machines such as photocopiers and printers. Such labels aid customers by indicating the environmental advantages of, say, low-energy light bulbs or reusable water bottles.

But carbon-labelling schemes are complicated, difficult for certifiers to validate and hard for consumers to understand. A household wanting to reduce the environmental impact of washing clothes has to navigate three different carbon footprints for the washing machine, the clothing and the detergent ${ }^{3}$. Sharing information on the carbon footprint of a product or service is often not in a company's best interests, so many choose not to.

Purchasing decisions based on carbon footprints tend to encourage only small, incremental changes to status-quo technologies. For example, purchasing a petrol car that is 5\% more fuel-efficient than previous cars will not reduce emissions by the aspired $80 \%$. Nor will it encourage the crucial switch to low-carbon energy sources ${ }^{4-6}$. Deep cuts in emissions demand more. The goal needs to be an electric car manufactured and driven in a region where electricity is generated from low- or zero-carbon sources.

I believe that publishing the level of dirtiness of electricity in the area where a product was produced or a service provided would be more powerful in swaying consumers, companies and states, and more effective in meeting global goals. The carbon intensity of electricity generation is a relatively simple measure for people to take in. It has 
values between 0 and about 1,000 tonnes of $\mathrm{CO}_{2} \mathrm{e} \mathrm{GWh}{ }^{-1}$, with a high value being bad.

Information on carbon intensity would accompany eco-labels, not replace them. Consumers wanting to purchase a microwave could still use energy ratings to judge how much electricity different machines would consume over the years. In addition, they could compare equally rated brands by where the electricity for the product's manufacture came from.

\section{CLEAN WINS}

In 2015 , electricity accounted for $18 \%$ of the world's energy at point of use. By 2050, or sooner, electricity must provide $50 \%$ or more of the energy consumed globally ${ }^{6}$ if it is to replace fossil fuels such as petrol and diesel in transport. Most or all of it must be generated from low-carbon sources such as wind, hydro and solar power ${ }^{4-6}$. Electricity with near-zero or even below-zero carbon intensity is the ultimate goal - and it is possible to achieve.

National electricity supplies vary widely in their carbon intensity ${ }^{7}$. Comparative global data are typically published with a 2-3-year lag, but values change slowly. As of 2014, South Africa was among the worst, with coal generating more than $90 \%$ of its electricity. China, India and Australia also rely heavily on coal; China produced nearly 1.5 times as much $\mathrm{CO}_{2}$ per unit of electricity as did the United States (see 'Regional ranges'). At the other end of the scale, Brazil achieves low emissions thanks to its substantial use of hydroelectric power; Sweden does so using a combination of hydropower, nuclear, wind, biofuels and waste; and Iceland achieves zero emissions through a combination of hydroand geothermal power.

National statistics are a guide, but for large countries they are too coarse to direct consumer decisions. There can be substantial geographical differences in the means of power generation within one country. The state or province is a reasonable area for reporting carbon intensity, because electricity generation is often regulated at this scale.

There are a host of socio-economic reasons why any company is based in a given place, as well as environmental considerations such as seasonal temperatures and water availability. Many of the highestcarbon US states are relatively poor and rely on the manufacturing industry for jobs. It is often not realistic, nor desirable, to force companies to move or close down. So I believe that those companies must push for innovation in the electricity sector.

Some might argue that companies should not be held responsible for state decisions on power generation, and that they do not have the influence to change things. But companies are increasingly environmentally minded, and are taking on social and political responsibilities typically ascribed

\section{REGIONAL RANGES}

Vastly different amounts of carbon dioxide are emitted to generate the same amount of electricity (carbon intensity) in different places. Regions within one country show as much variation as do different nations.

\section{CARBON INTENSITY: $\quad$ Highest $\quad$ Lowest}

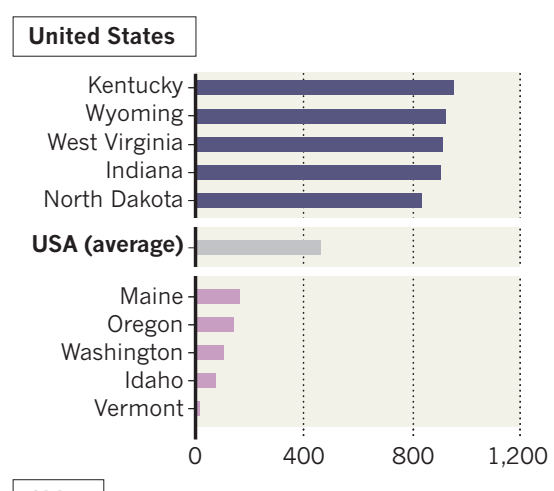

\section{China}

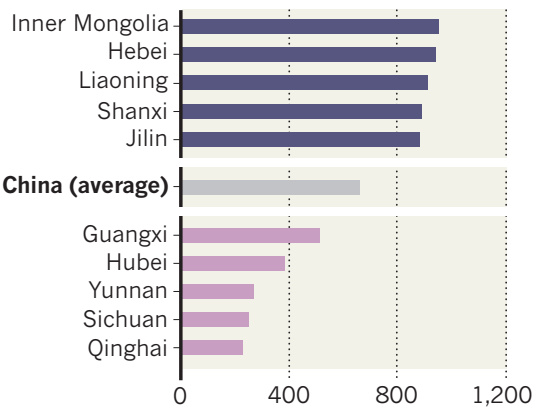

Other industrialized nations

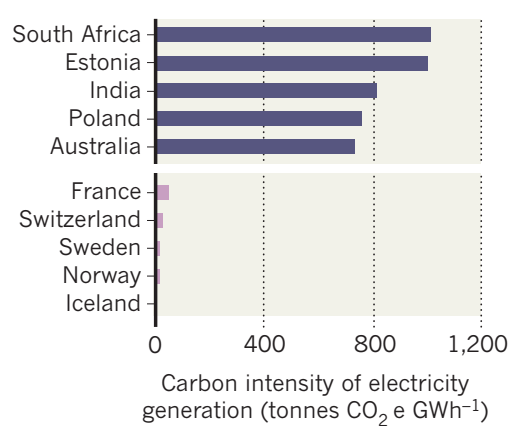

to governments ${ }^{8}$.

The Toyota Motor Corporation, for example, is a leader in the production of hybrid and other low-carbon vehicles. Yet its largest US assembly plant is located in Georgetown, Kentucky. On the basis of the electricity required to assemble a typical car (around 1,500 kilowatt hours) ${ }^{9}$, I estimate that producing 550,000 vehicles there in 2014 could have released emissions of around 735,000 tonnes of $\mathrm{CO}_{2} \mathrm{e}$. That is equal to the total annual emissions of a US city with a population of 40,000 .

GE Appliances, now owned by Chinese conglomerate Haier, based in Qingdao, produces more than 4 million domestic appliances in Louisville, Kentucky, each year. $\mathrm{GE}$ is committed to reducing pollution from the disposal and transport of its goods. Yet assembling a typical washing-machine-sized appliance (requiring about 1,000 megajoules of energy) in 2014 using Kentucky's electricity would have emitted about $260 \mathrm{~kg}$ of $\mathrm{CO}_{2} \mathrm{e}$ compared with 3 kilograms $\mathrm{CO}_{2} \mathrm{e}$ if it had been assembled in Vermont.

Service companies use electricity for cooling, electronics, lighting and heating of office buildings. The annual greenhousegas emissions from electricity use in a typical 9,000-square-metre office building in a 'dirty' state are three to six times higher than those from equivalent buildings in California, Washington state or New York state.

\section{NEXT STEPS}

Phasing out fossil fuels rapidly from electricity generation is essential for cutting global carbon emissions. To guide purchasing decisions people need accessible and current data on the carbon intensities of electricity in countries and their various regions. Published estimates are typically from three or more years ago; more recent ones would ensure that pressure is exerted where it is needed most. National environmental agencies, the International Energy Agency and nongovernmental organizations must disseminate such data to the public and to companies.

Companies should make clear where products are made - in particular, where electricity is most used in the product supply chain or in the offices of a service company. Companies based in high-carbon states might consider switching to renewables, following the lead of Target, Walmart, Apple and IKEA.

Climate campaigners should raise awareness of this issue and call for boycotts. Better informed consumers and corporations would help speed the world's transition to clean energy.

Christopher Kennedy is a professor of industrial ecology and chair of civil engineering at the University of Victoria, Canada.

e-mail:cakenned@uvic.ca

1. Kennedy C. Nature Clim. Change 5, 179-181 (2015).

2. Bulkeley, H. et al. Transnational Climate Change Governance (Cambridge Univ. Press, 2014).

3. Cullen, J. M. \& Allwood, J. M. J. Ind. Ecol. 13, 27-37 (2009)

4. Intergovernmental Panel on Climate Change. Fifth Assessment Report, Working Group 3, Ch. 7, 7.11.3 (IPCC, 2014).

5. Rogelj, J. et al. Nature Clim. Change 5, 519-527 (2015).

6. Williams, J. H. et al. Science 335, 53-59 (2012).

7. International Energy Agenc. $\mathrm{CO}_{2}$ Emissions from Fuel Combustion (IEA, 2016).

8. Scherer, A. G. \& Palazzo, G. J. Manag. Studies 48, 899-931 (2011)

9. Sullivan, J. L., Burnham, A. \& Wang, M. “Energyconsumption and carbon-emission analysis of vehicle and component manufacturing' (No. ANL/ESD/10-6) (Argonne National Laboratory, 2010).

10.Qu, S., Liang, S. \& Xu, M. Environ. Sci. Technol. 51, 10893-10902 (2017). 